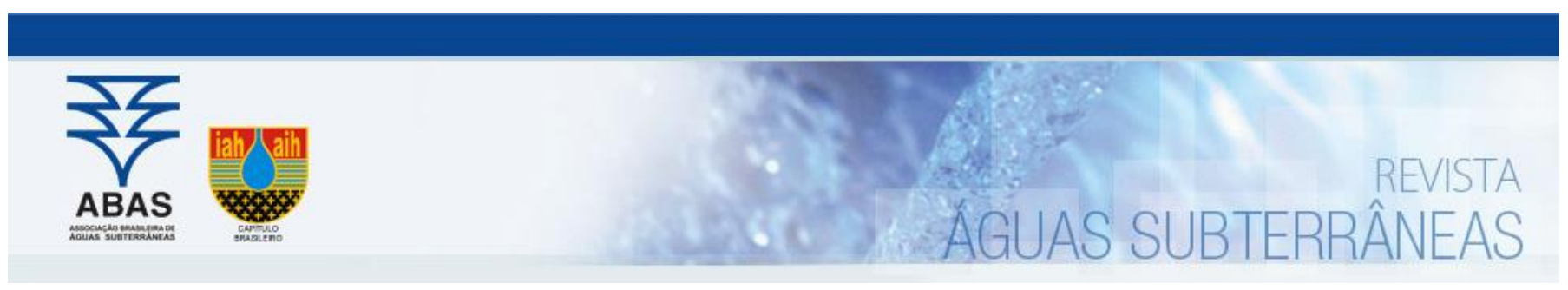

Artigos

\title{
Métodos WTF e simulação numérica de fluxo para estimativa de recarga - exemplo Aquífero Rio Claro em Paulínia/SP
}

\section{WTF and numerical flow simulation methodologies to groundwater recharge estimation - example of Rio Aquifer in Paulínia/SP}

\author{
Elias Hideo Teramoto1,2; Hung Kiang Chang1,2,3凶 \\ ${ }^{1}$ Lebac - Laboratório de Estudos de Bacias, Instituto de Geociências e Ciências Exatas, UNESP - Campus de Rio Claro, SP \\ 2 Centro de Estudos Ambientais (CEA), UNESP - Campus de Rio Claro, SP \\ ${ }^{3}$ Departamento de Geologia Aplicada, Instituto de Geociências e Ciências Exatas, UNESP - Campus de Rio Claro, SP

\section{teramoto@rc.unesp.br, chang@rc.unesp.br}

\begin{abstract}
Resumo
A estimativa do volume de recarga dos aquíferos é fundamental para o gerenciamento de recursos hídricos de subsuperfície. Parte da área de ocorrência do aquífero Rio Claro no munícipio de Paulínia/SP é marcada pela presença de hidrocarbonetos na fase residual e influência de poços de bombeamento dos sistemas de remediação em operação, além de incertezas associadas a heterogeneidades geológicas peculiares a essa unidade hidrogeológica. Esses fatores dificultam estimativas seguras de recarga. Para contornar o problema, foram realizadas simulações numéricas de fluxo, em regime transiente, utilizando dados de monitoramento levantados ao longo de 7 anos, para estimar a recarga do Aquífero Rio Claro nessa área. As variações de carga hidráulica da simulação são similares às variações do nível d'água em todos os poços monitorados, indicando que o modelo fo satisfatoriamente calibrado. A comparação entre as estimativas de recarga pelo método Water Table Fluctuation e os valores obtidos pelos modelos matemáticos revelam elevada discrepância entre ambos. Tal discrepância está associada à diferença nos valores do parâmetro Sy (produtividade específica) empregados nos diferentes métodos. Os valores de Sy podem promover taxas de recarga do aquífero superestimadas por não contemplar o efeito da histerese durante a flutuação do nível d'água.

Abstract

The estimative of groundwater recharge volume of is a crucial requirement for the management of subsurface water resources. A portion of the Rio Claro aquifer in the municipality of Paulínia/SP is marked by the uncertainties related to geological heterogeneities, the presence of hydrocarbons in the residual phase and the influence of pumping wells of the active remediation systems. As a result of these factors, reasonable recharge estimations are hampered. In order to overcome the mentioned difficulties, numerical simulations of transient flow were carried out to estimate recharge in a portion of the Rio Claro aquifer in the municipality of Paulínia/SP. Since the hydraulic head variations of the simulation are similar to the variations in all wells monitored during the simulated 7 years (2007-2014), this model was considered representative. The comparison of recharge estimation provided by the WTF (water table fluctuation) method and the mathematical model values showed high discrepancies between both. These discrepancies are associated to the difference in the values used for the specific yield parameter in both methods. The results of the present work suggest that the values of Sy and the recharge estimates can promote overestimations in the rates of recharge of the aquifer because it does not contemplate the effect of the hysteresis during the water table fluctuation.
\end{abstract}

Palavras-chave:

Aquífero Rio Claro

Simulação numérica de fluxo.

Recarga.
Flutuação do nível d'água.

\section{Keywords}

Groundwater recharge.

Rio Claro aquifer.

Numerical flow simulation.

Water table fluctutation.

Revisado por pares.

Recebido em: 22/09/2017.

Aprovado em: 24/04/2018.

\section{INTRODUÇÃO}

A estimativa das taxas de recarga de aquíferos é imperativa para a adequada gestão de recursos hídricos subterrâneos. Uma vez que a recarga não pode ser diretamente medida, uma ampla gama de métodos, que variam em escala e complexidade, foram propostos para sua estimativa (HEALY \& COOK, 2002; SCALON et al., 2002). Esses métodos podem fornecer resultados bastante discrepantes entre si (SCANLON et al., 2002; YIN et al., 2011; SAGHRAVANI et al., 2015; KING et al., 2017).
Em razão da facilidade de cálculo, é comumente empregado o método WTF (Water Table Fluctuation), que calcula a recarga a partir do registro das variações sazonais do nível d'água (NA). 0 valor de recarga estimado pelo método WTF é aplicado para uma porção pontual do aquífero e, portanto, sua representatividade é restrita, uma vez que a recarga é um parâmetro espacialmente variável. Cabe ainda ressaltar que o método WTF possui alta sensibilidade ao parâmetro produtividade específica do aquífero $\left(S_{y}\right)$ e, por esta razão, existem fortes incertezas relacionadas a esta estimativa, 
uma vez que valores reais $S_{y}$, na maioria dos casos, não são determinados. A não determinação de Sy está relacionada à dificuldade de se obter amostras indeformadas em porções profundas do aquífero para a realização de ensaios de curvas de retenção.

0 ingresso de água em sub-superfície altera as condições iniciais de umidade no solo. O potencial matricial do solo é dependente do teor de umidade em uma condição de equilíbrio, sendo esta relação definida pelas curvas de retenção (van GENUCHTEN, 1981). No evento de drenagem, a água em um meio poroso integralmente saturado é drenada do solo fazendo com que a umidade do solo caia e o potencial matricial aumente, seguindo a curva de drenagem. Na direção oposta, quando a água ingressa no sistema de poros do aquífero, existe o fenômeno de embebição, na qual o teor de umidade do sedimento aumenta e o potencial matricial cai, descrevendo a curva de embebição. Durante o ciclo de embebição parte dos poros do aquífero, particularmente os poros grandes, resiste ao preenchimento por água e não são saturados. Uma vez que os volumes de água envolvidos nos ciclos drenagem e embebição são distintos, as curvas de drenagem e embebição não se sobrepõem. Neste caso, a curva de drenagem apresentará um valor maior de potencial matricial que a curva de embebição para um mesmo valor de umidade, sendo este fenômeno conhecido por histerese.

Em decorrência do efeito de histerese, existem dois parâmetros de armazenamento distintos para aquíferos livres, a "produtividade específica" (Sy) e a "porosidade preenchível" ( $\left.\Theta_{f}\right)$ (CHILDS,1960; KAYANE,1983; SOPHOCLEOUS, 1991; HEALY \& COOK, 2002; ACHARYA et al., 2012), embora apenas a primeira seja empregada para estimativas de recarga. A produtividade específica pode ser definida como o volume de água liberada de um volume unitário do aquífero saturado por uma queda do nível d'água (NA). Em contraponto, a porosidade preenchível é a quantidade de água que um aquífero não confinado pode armazenar por unidade de elevação na água e por unidade de área. Em resposta ao efeito da histerese, onde apenas parte do espaço poroso do aquífero é preenchida por água durante o evento de embebição, o valor de $\Theta_{\mathrm{f}}$ será sempre menor que $S_{y}$ (SOPHOCLEOUS, 1991).

Os modelos numéricos de fluxo representam importantes alternativas ao método WTF para estimativas de recarga (JYRKAMA et al., 2002, RABELO \& WENDLAND, 2009; SREEKANTH et al.,2015 e WANG et al., 2015). Os parâmetros de entrada do modelo, incluindo as taxas de recarga e os valores de $S_{y}$, são determinados a partir de ajustes sucessivos dos valores atribuídos a esses parâmetros.

Assim, com vistas a quantificar a recarga em uma área do Aquífero Rio Claro no munícipio de Paulínia (SP), foram empregados modelos numéricos de fluxo, em regime transitório, considerando um período de 7 anos consecutivos (2007-2014). Por intermédio destas simulações, foi objetivo deste trabalho identificar a variabilidade espacial e temporal das taxas de recarga, assim como comparar com os resultados obtidos com estimativas fornecidas pelo método WTF.

\section{1. Área de Estudo}

A área de estudo situa-se no munícipio de Paulínia, porção centroleste do Estado de São Paulo. Ocorrem aí rochas sedimentares atribuídas ao Subgrupo Itararé (Carbonífero-Permiano) e à Formação Rio Claro (Cenozoico), unidades litoestratigráficas da Bacia do Paraná, além de depósitos aluvionares recentes (Figura 1).

Figura 1 - Mapa geológico da região de Paulínia (Modificado de FERNANDES, 1997) e localização da área de estudo

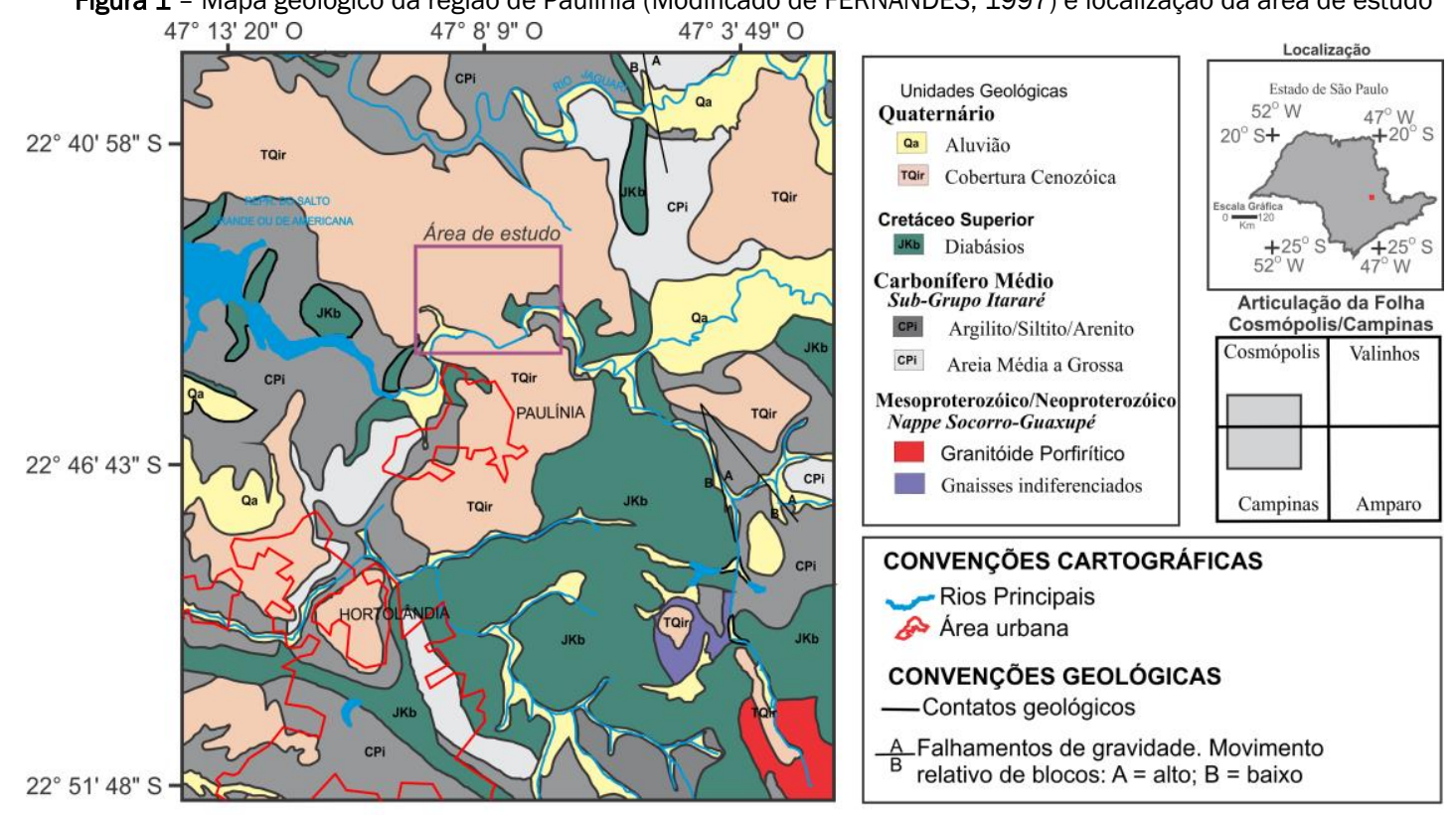

\section{MATERIAIS E MÉTODOS}

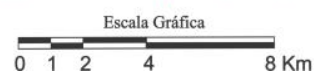

Como descrito por Pede (2009), o Aquífero Rio Claro é representado na área por fácies de canal (areia média a grossa microconglomerática e areia média argilosa) e fácies de planície de inundação (silte argiloso e argila arenosa). Uma vez que a condutividade hidráulica é intrinsicamente relacionada às variações litológicas do aquífero, a heterogeneidade geológica é refletida por amplas variações de condutividade hidráulica $(\mathrm{K})$, abrangendo valores entre $1,2 \times 10^{-7}$ $\mathrm{m} / \mathrm{s}$ e $2,4 \times 10^{-4} \mathrm{~m} / \mathrm{s}$ (TERAMOTO \& CHANG, 2017).

Parte da área estudada no presente trabalho está contaminada por querosene de aviação, com um volume estimado de $520 \mathrm{~m}^{3}$ (PEDE, 2009). Desde 2005 está ativo na área um sistema de remediação, por meio de bombeamento e tratamento, para recuperação de fase livre em subsuperfície; atualmente, 20 poços de bombeamento estão em operação na área. Embora se destinem a promover a 
recuperação de LNAPL (Ligth Non Aqueous Phase Liquid), esses poços extraem grande volume de água, podendo afetar diretamente as variações do NA.

\subsection{Estimativa da Recarga pelo Método WTF}

Para interpretar os ciclos de flutuação sazonal do NA na área de estudo foram levantadas informações pluviométricas da Estação D4-46, próxima da área de estudo e disponível para consulta no site do DAAE. Neste site estão disponíveis dados desde o ano de 1958, possibilitando avaliar a existência de índices pluviométricos anômalos no período analisado no presente trabalho.

Desde 2003 está implantado na área um programa de monitoramento do NA, com frequência quinzenal, sendo possível avaliar a variação temporal do nível piezométrico do aquífero local. Poços em que foi registrada a presença de fase livre não foram avaliados no presente estudo.

A estimativa da recarga líquida anual pelo método WTF foi conduzida a partir da série histórica da flutuação do NA. A partir da hidrógrafa dos poços de monitoramento foi determinado o valor de $\Delta \mathrm{H}$ (diferença entre o pico de ascensão do NA e a curva resultante da extrapolação de recessão). A recarga líquida anual ( $R$ ) é estimada a partir do produto entre $\Delta \mathrm{H}$ e a produtividade específica do aquífero (Sy):

$$
R=\Delta H * \mathrm{Sy}
$$

Pede (2009) determinou os valores de $S_{y}$ a partir de curvas de retenção em amostras indeformadas dos principais tipos litológicos que constituem o Aquífero Rio Claro, identificando valores entre 0,079 e 0,29 .

O método WTF oferece como vantagem a possibilidade de estimar a recarga de maneira simples, requerendo apenas dados obtidos pela medição periódica do nível d'água. Contudo, não existem métodos para avaliar se os valores empregados de $S_{y}$ são adequados. Além disso, salienta-se que o método WTF não deve ser aplicada em regimes próximas de zonas de descarga (ex. zonas hiporreicas).

\subsection{Simulação de Fluxo em Regime Transiente}

A distribuição dos valores de condutividade hidráulica e $S_{y}$ obedeceu à distribuição de condutividade hidráulica no modelo. Com o emprego do aplicativo Visual MODFLOW 2010, baseado no aplicativo MODFLOW 2005 (HARBAUGH, 2005), foram geradas simulações com o intuito reproduzir as flutuações do NA ao longo de 2610 dias, correspondente ao período situado entre 15/08/2007 e $07 / 10 / 2014$.

O domínio do modelo foi discretizado em malha com 288 linhas, 296 colunas e 6 camadas. Para melhor representação dos poços de bombeamento, foi realizado um refinamento no espaçamento progressivo das linhas e colunas em torno destes poços. Em virtude da discretização adotada, o espaçamento das células que representam os poços de bombeamento foram 2 vezes menores que as células distantes destes poços. A definição dos limites entre as camadas do modelo levou em consideração as variações geológicas em profundidade.

Para representar a extração de água por bombeamento, foi reproduzido o regime de bombeamento registrado nos poços em operação no sistema de remediação (Figura 2). Os rios foram representados por Condições de Contorno Rios (terceiro tipo), e os corpos d'água de pequeno porte foram representadas por Contornos de Carga Fixa (primeiro tipo) (Figura 2). A calibração do modelo foi realizada mediante a comparação entre os valores de carga hidráulica, calculadas pela simulação, e os valores medidos em campo nos poços de observação em 101 poços de monitoramento empregados como referência para calibração do modelo.

Figura 2 - Domínio do modelo, distribuição das condições de contorno e dos poços de monitoramento e bombeamento empregados na simulação

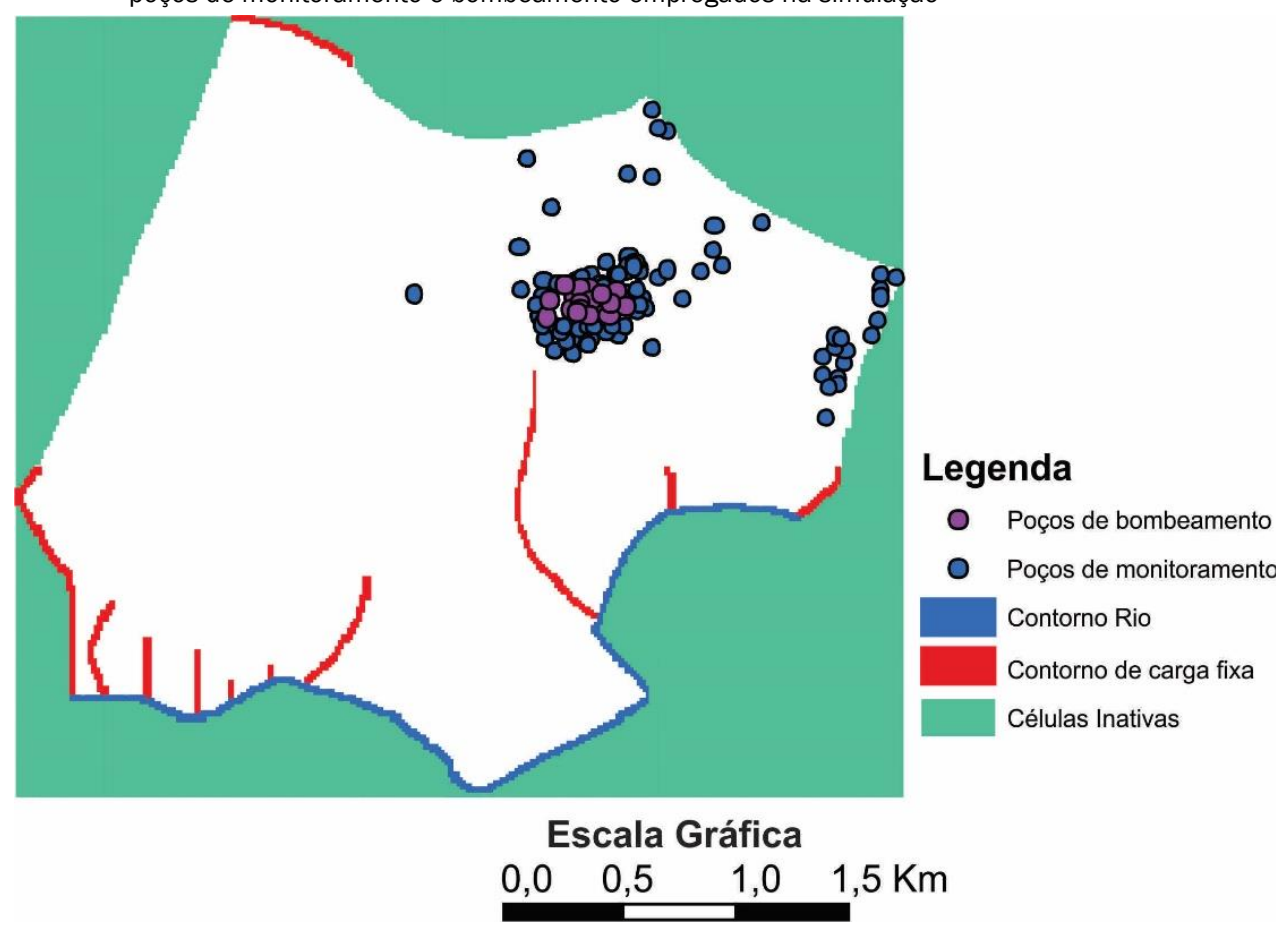




\section{RESULTADOS}

\subsection{Flutuação do Nível D'água}

Do ponto de vista hidrológico, as variações anuais de precipitação na área de estudo são marcadas por períodos contrastantes, com baixas precipitações entre os meses de abril e outubro, alternandose com períodos de precipitação intensa entre novembro e março (Figura 3), e máximos valores no mês de janeiro. As variações nas taxas de precipitação ao longo do ano são responsáveis pelas variações nas taxas de recarga e, consequentemente, pela flutuação do NA. As hidrógrafas dos poços de monitoramento (Figura 3) indicam que a oscilação do NA representa um fenômeno cíclico anual, em que a subida se inicia no mês de janeiro e prossegue até atingir o ápice no mês de maio. A partir desse ponto, a carga hidráulica declina até o mês de janeiro, quando um novo ciclo de subida se inicia. É possível notar que existe um descompasso de aproximadamente 3 meses entre o período em que a pluviometria aumenta (Outubro) e o período em que o NA inicia sua ascensão (Janeiro).

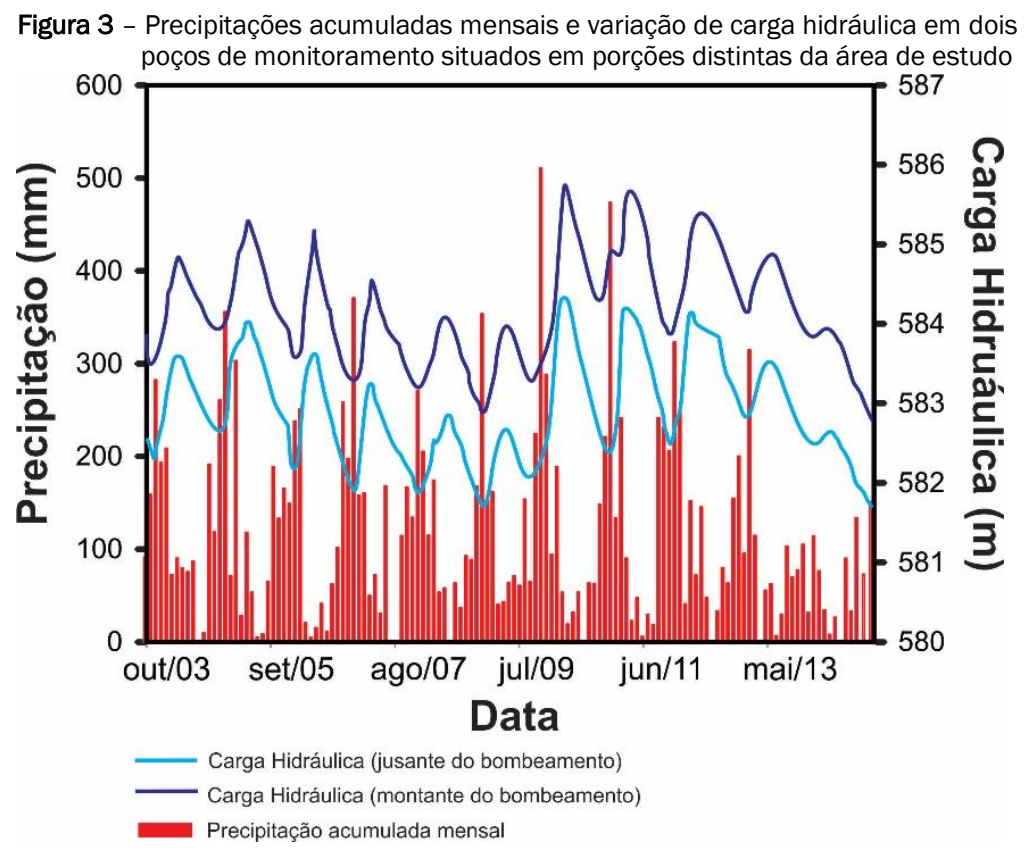

\subsection{Estimativa de Recarga pelo Método WTF}

As estimativas da recarga pelo método WTF foram realizadas para todos os poços com séries históricas contínuas do NA empregando a relação apresentada na Equação 1. No presente trabalho, o valor de $S_{y}$ igual a 0,22 foi considerado o mais representativo para a área de estudo, tendo sido empregado em todos os cálculos de recarga líquida pelo método WTF. A adoção deste valor se justifica pelo fato deste valor estar associado à litologia areia média a grossa argilosa
(PEDE, 2009), predominante no intervalo de profundidade onde ocorre a flutuação do nível d'água. A partir das curvas de variação do nível d'água foram obtidos graficamente os valores de $\Delta \mathrm{H}$ (Figura 4a). Com base nos valores de recarga líquida determinados nos poços de monitoramento analisados, foram elaborados mapas com a distribuição espacial de recarga (Figura 4b).

Figura 4 - a) Determinação dos valores de $\Delta H$, ao longo de 7 anos consecutivos (2007-2014), para estimativa da recarga anual líquida pelo método WTF; b) Isovalores de recarga líquida no ano de 2012 estimados pelo método WTF

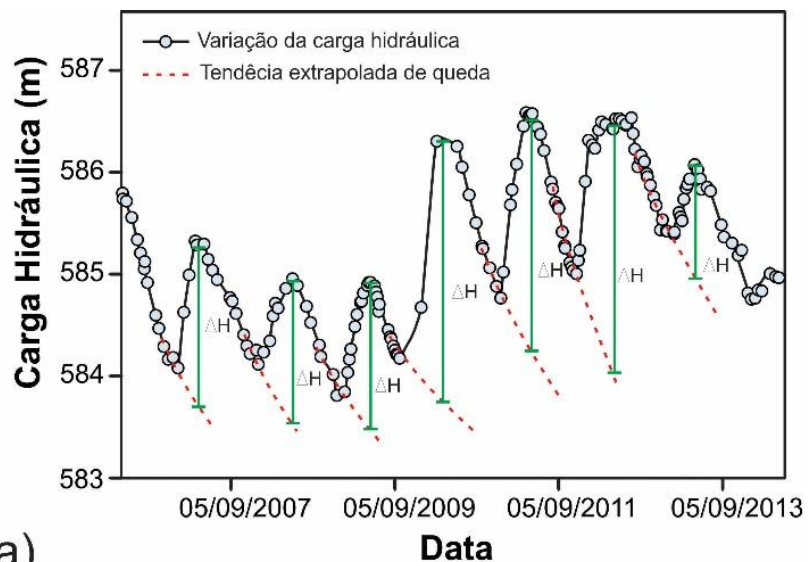

a)

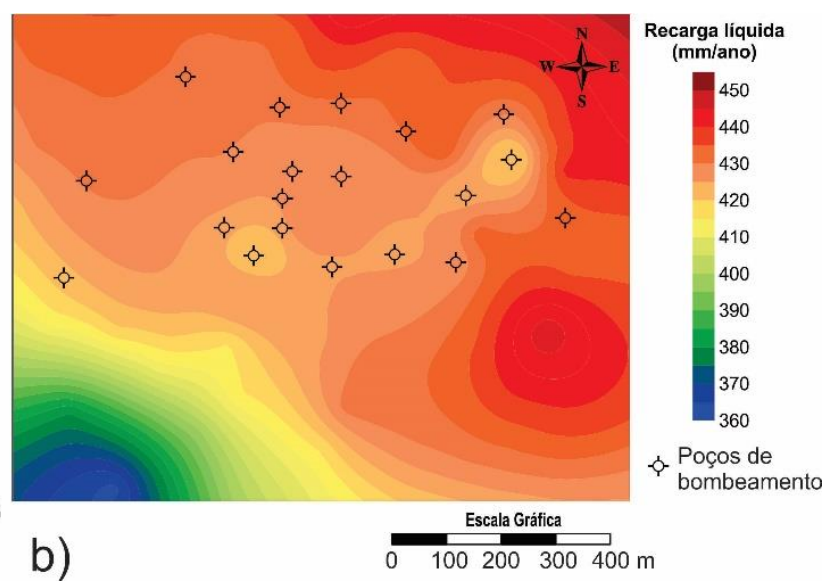


Na Figura 4b é possível verificar que os maiores de valores recarga distribuem-se na porção NE e decrescem progressivamente na direção SW, em direção a uma drenagem, que constitui uma importante zona de descarga local. É possível notar que os valores estimados de recarga são menores nas proximidades dos poços de bombeamento do que em porções externas adjacentes.
Os valores médios de recarga líquida determinados nos poços de monitoramento, a precipitação acumulada anual e as razões de recarga/precipitação são apresentados na Tabela 1.

Tabela 1 - Precipitação acumulada anual, recarga líquida e razão recarga/precipitação

\begin{tabular}{cccc}
\hline Ano & Precipitação $(\mathrm{mm})$ & Recarga $(\mathrm{mm})$ & Precipitação/Recarga \\
\hline 2007 & 1427,60 & 335,50 & 0,25 \\
2008 & 1326,50 & 339,24 & 0,24 \\
2009 & 1902,90 & 378,40 & 0,29 \\
2010 & 1225,40 & 529,10 & 0,28 \\
2011 & 1743,30 & 403,92 & 0,33 \\
2012 & 1361,50 & 467,50 & 0,27 \\
2013 & 1131,40 & 257,09 & 0,19 \\
2014 & 943,60 & 153,12 & 0,14 \\
\hline
\end{tabular}

\subsection{Resultados dos modelos de fluxo em regime transiente}

Os valores de $\mathrm{K}$ e Sy se basearam na distribuição litológica de subsuperfície, determinada a partir de investigações ambientais e geotécnicos conduzidas na área. Inicialmente foram empregados valores de $S_{y}$ iguais aos determinados por Pede (2009). Esse autor determinou valores de Sy iguais a 0,079 para litologias silto-argilosas, 0,22 para areias médias argilosas e 0,29 para areias médias a grossas microconglomeráticas. Contudo, esses valores não possibilitaram reproduzir a queda observada do nível d'água, sendo necessário promover a redução destes valores para alcançar a calibração do modelo. Os valores obtidos valores de $S_{y}$ nos ajustes dos modelos foram em média $40 \%$ menores na primeira camada do modelo em comparação com os valores determinados por curva de retenção e apresentados por Pede (2009).

A Figura 5 ilustra a comparação entre os valores de carga hidráulica observada e calculada na simulação, em regime permanente (Figura 5a), e nos 4175 dados de todo o período simulado em regime transiente (Figura $5 b$ ). Notabiliza-se que as diferenças entre tais valores são bastante reduzidas, com erro RMS normalizado inferior a $5 \%$, indicando a calibração do modelo em ambos os casos.

Figura 5 - Gráfico de dispersão dos valores observados e simulados de carga hidráulica. a) em regime permanente no dia 15/08/2007; b) nos 2160 dias de simulação em regime transiente

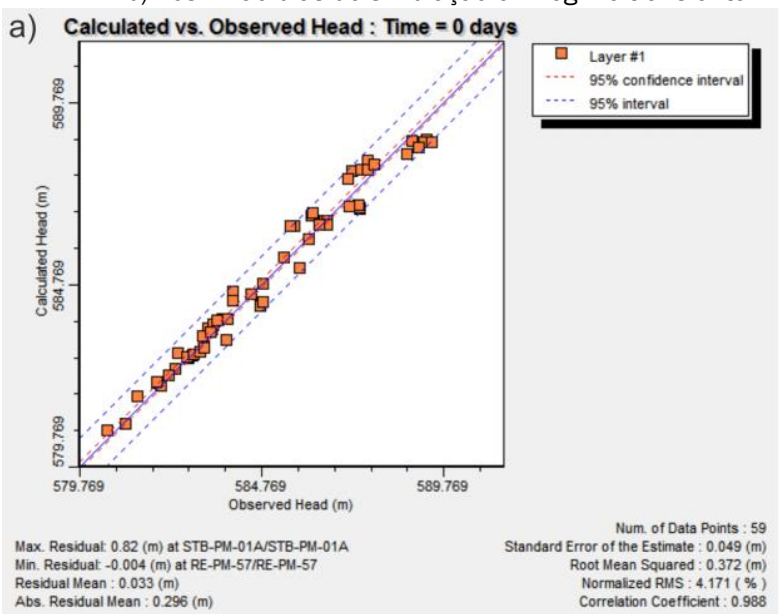

A comparação das variações da carga hidráulica observadas e calculadas, em diferentes porções da área estudada, ao longo dos 7 anos (Figuras 6a-d), indica que a simulação em regime transiente

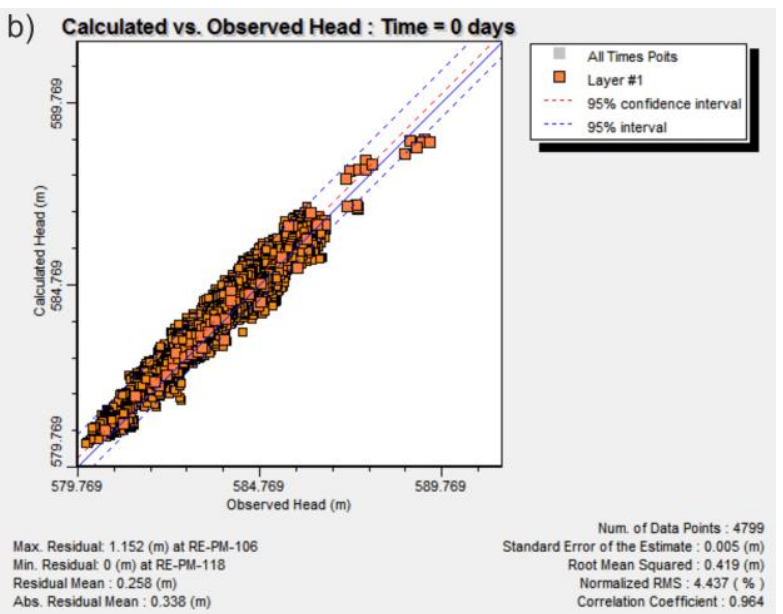

foi capaz de reproduzir a ciclicidade e a amplitude da flutuação do NA. 
Figura 6 - Variação observada e simulada da carga hidráulica em diferentes poços de monitoramento. a) Poço de monitoramento situado a jusante da influência dos poços de bombeamento; b) e c) Poços de monitoramento situados na região sob influência direta dos poços de bombeamento; d) Poço de monitoramento situado à montante da área de influência do bombeamento
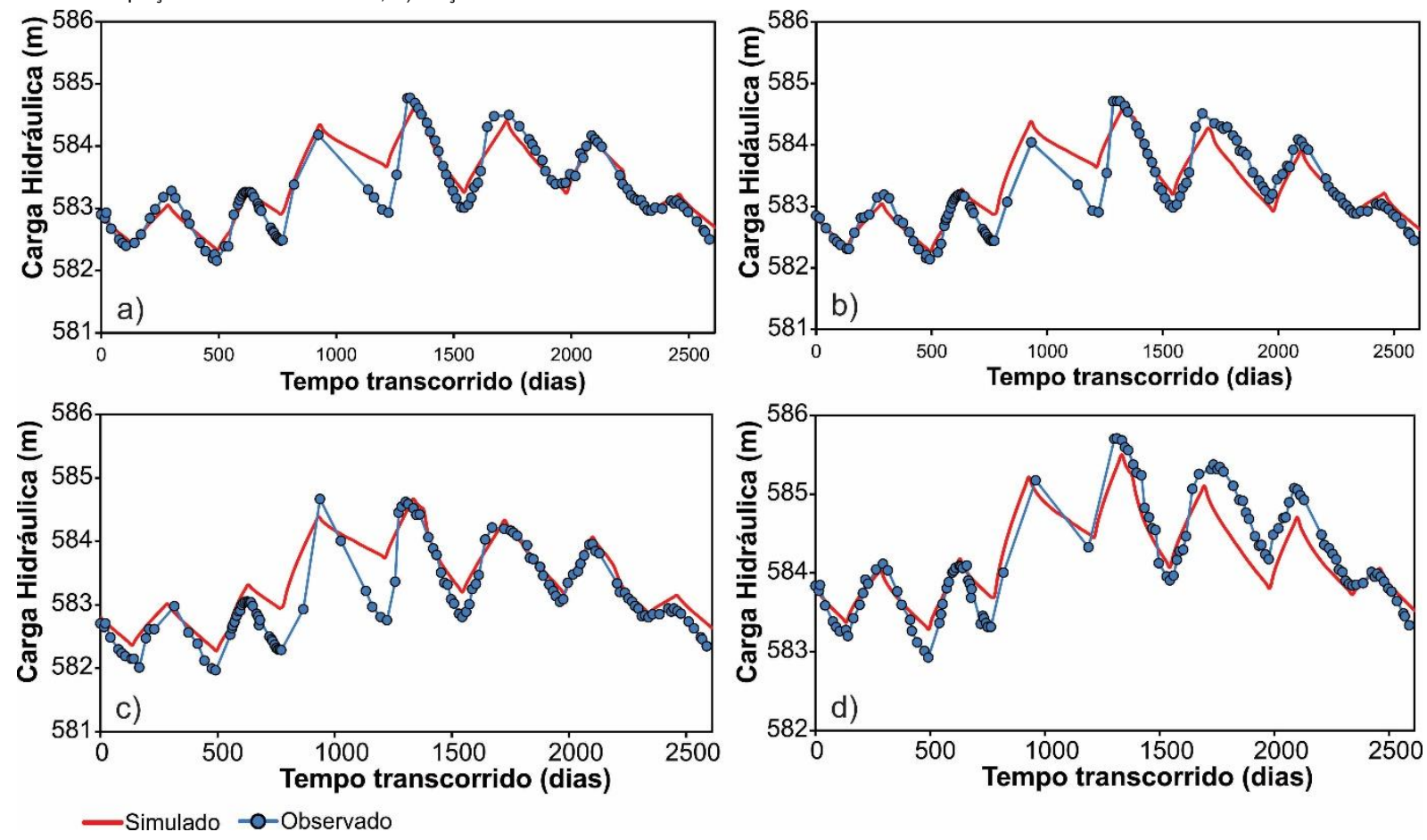

Durante a calibração do modelo foram definidas oito zonas com valores distintos de recarga (Figura 7). Estas zonas de recarga foram definidas adotando-se a premissa que o volume de recarga é menor em casos onde o gradiente topográfico é maior, onde existe o predomínio de rochas pouco permeáveis e em porções situadas nas proximidades das zonas de descarga.

A Tabela 2 apresenta os valores de recarga para cada zona de condutividade, nos 7 anos de simulação, para as oito zonas de recarga definidas na simulação.

Figura 7 - Distribuição das diferentes zonas de recarga empregadas nas

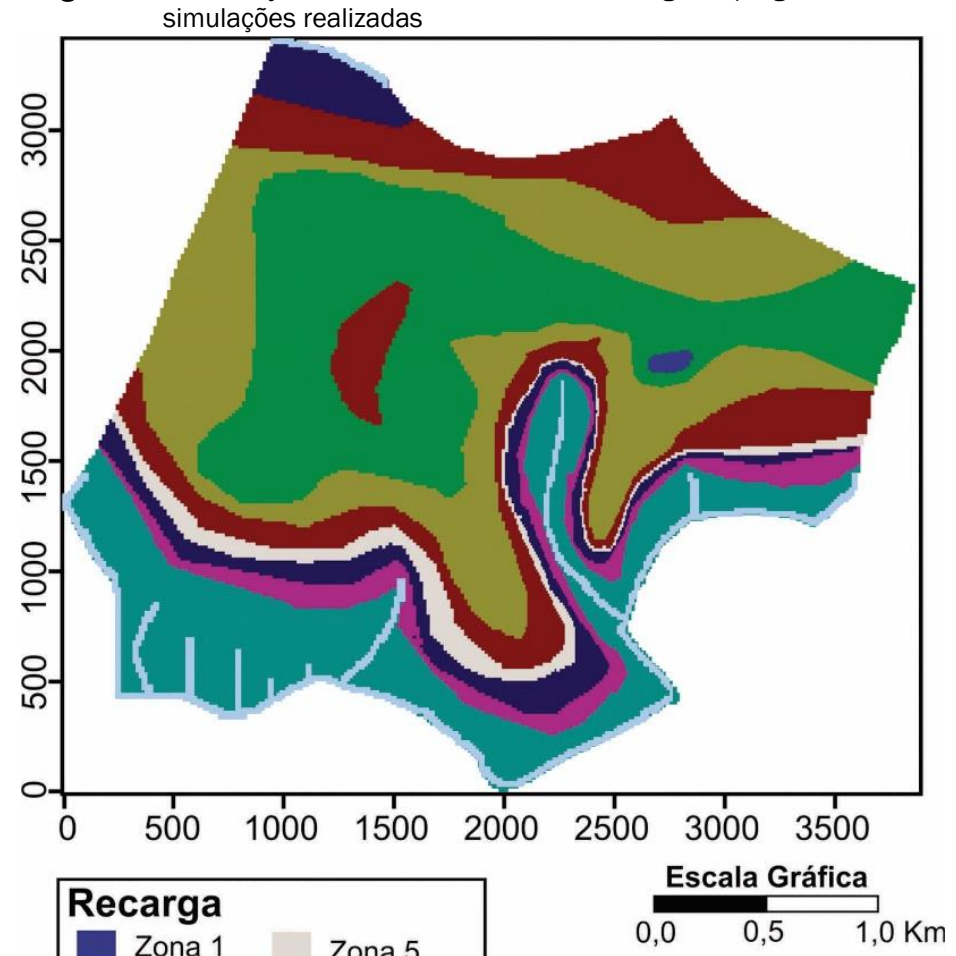

Zona 2

Zona 3

Zona 4

Zona 6

Zona 7

Zona 8

Condições de contorno 
Tabela 2 - Valores de recarga calibrados para as oito zonas definidas no modelo de fluxo em regime transiente.

\begin{tabular}{cccccccc}
\hline \multirow{2}{*}{ Zona } & \multicolumn{7}{c}{ Ano } \\
& 2008 & 2009 & 2010 & 2011 & $\mathbf{2 0 1 2}$ & $\mathbf{2 0 1 3}$ & $\mathbf{2 0 1 4}$ \\
\hline 1 & 203,4 & 226,0 & 262,2 & 248,6 & 271,2 & 226,0 & 135,6 \\
2 & 171,8 & 203,4 & 239,6 & 226,0 & 244,1 & 207,9 & 90,4 \\
3 & 72,3 & 96,8 & 135,6 & 113,0 & 153,7 & 144,7 & 72,3 \\
4 & 63,3 & 67,8 & 99,5 & 81,4 & 117,5 & 99,5 & 54,2 \\
5 & 40,7 & 40,7 & 40,7 & 40,7 & 40,7 & 40,7 & 31,6 \\
6 & 22,6 & 22,6 & 22,6 & 22,6 & 22,6 & 22,6 & 18,1 \\
7 & 9,0 & 9,0 & 9,0 & 9,0 & 9,0 & 9,0 & 6,8 \\
8 & 4,5 & 4,5 & 4,5 & 4,5 & 4,5 & 4,5 & 2,3 \\
\hline
\end{tabular}

\section{DISCUSSÃO}

No período compreendido pelo presente trabalho (2007-2014) foram registrados dois anos bastante contrastantes com relação aos dados históricos (1958-2015) de pluviometria acumulada anual. No ano de 2009, a precipitação acumulada anual foi de 1902,90 mm, que representa um valor $501,20 \mathrm{~mm}(36 \%)$ superior à média história registrada. Situação oposta verifica-se no ano de 2014, quando foi registrada precipitação acumulada anual de $943,60 \mathrm{~mm}$, que representa um valor 438,10 mm (31\%) abaixo da média histórica.

Os contínuos ajustes nos parâmetros de entrada do modelo permitiram reproduzir a flutuação sazonal e as amplitudes de variação do NA observadas em campo ao longo de 7 anos (Figuras 5b e 6), indicando que as simulações foram calibradas para o período considerado. As taxas de recarga obtidas nas simulações são amplamente variáveis e ocorrem apenas em 165 dias do ano, entre os meses de janeiro e maio. Quanto à distribuição espacial da recarga, os maiores valores de recarga tendem a se concentrar próximos dos divisores de fluxo subterrâneo, a norte, e decrescerem progressivamente para sul, em direção às zonas de descarga (Figura 7). Os menores valores de recarga se encontram na meia-encosta, onde o declive do terreno e a presença de litologias pouco permeáveis favorece o escoamento superficial.

A média dos valores de recarga anuais líquidos obtidos pelo método WTF (Tabela 1) indicam que esta corresponde a $25 \%$ da precipitação anual acumulada, percentual este superior ao obtido pela calibração dos modelos matemáticos. As Zonas 1, 2 e 3 respondem pela maior parte da recarga na área de estudo e estão situadas em uma porção plana, onde o escoamento superficial ocorre de maneira menos efetiva. A média da razão recarga/precipitação acumulada anual nas Zonas 1, 2, 3 e 4 são, respectivamente, 16\%, 15\%, $9 \%$ e $6 \%$ da precipitação total anual. Considerando apenas a área onde foi efetuado o cálculo de recarga pelo WTF (Figura 4b), a média ponderada da recarga emprega no modelo é de $13,2 \%$ da precipitação acumulada anual, valores $47,2 \%$ inferior aos obtidos pelo método WTF.

A discrepância entre as estimativas de recarga fornecidas pelo método WTF e as simulações numéricas de fluxo em regime transiente decorre das diferenças dos valores de $\mathrm{S}_{\mathrm{y}}$ empregados em ambos os métodos. Embora a diferença entre as estimativas de recarga pelo método WTF e modelos matemáticos possa ser associada às incertezas do parâmetro $S_{y}$, é igualmente provável que os valores de $S_{y}$ mensurados por curvas de retenção sejam inapropriados para as estimativas de recarga. As variações sazonais do NA podem ser interpretadas como ciclos recorrentes de embebição e drenagem do meio poroso na porção superior da zona saturada. Em períodos em que o NA sobe, parte do espaço poroso não é passível por preenchimento por água. Dessa maneira, o volume de poro efetivamente preenchido por água proveniente da recarga é menor do aquela baseada nos valores de $S_{y}$ e, por essa razão, estimativas realistas de recarga devem empregar o parâmetro $\Theta_{f}$ em vez de $S_{y}$. Os valores calibrados de $S_{y}$ na primeira camada foram $40 \%$ inferiores aos valores obtidos laboratorialmente. Tendo em vista que a primeira camada corresponde ao intervalo onde ocorre a flutuação do NA, os valores calibrados de $S_{y}$ possivelmente refletem o parâmetro $\Theta_{f} \mathrm{e}$ esta constatação deve ser melhor investigada. A presença de hidrocarbonetos na forma residual no interstício poroso promove uma redução adicional significativa do volume de poro preenchível por água. Uma vez que a saturação da fase líquida não-aquosa $\left(S_{n w}\right)$ no meio poroso é variável, a redução na porosidade é igualmente variável, tornando as estimativas de recarga mais complexas em áreas contaminadas por LNAPL, elevando o grau de incertezas.

A influência dos poços de bombeamento pode induzir a erros nas estimativas de recarga pelo método WTF. Face aos significativos volumes de água subterrânea extraídos com a operação do sistema de remediação instalado na área, as estimativas de recarga podem estar subestimadas. 0 mapa de distribuição de recarga pelo método WTF (Figura $4 b$ ) indica que os valores de recarga próximos dos poços de bombeamento são menores do que em porções externas adjacentes. Esses valores menores de recarga próximos aos poços de bombeamentos decorrem da atenuação da amplitude de ascensão do $\mathrm{NA}(\Delta \mathrm{H})$ durante os períodos de recarga do aquífero, induzindo à subestimação dos valores estimados de recarga. Desta sorte, é necessário ressaltar que a representatividade do método WTF é reduzida próximo de poços de bombeamento e, nestes casos, o emprego deste método não é recomendada.

No método numérico de diferenças finitas, o poço de bombeamento é representado por uma célula inteira do modelo e os efeitos do bombeamento são fortemente dependentes das dimensões desta célula. Neste caso, é recomendável um refinamento da malha na região onde estão situadas os poços de bombeamento para a representação mais realista do efeito do rebaixamento promovido pela extração de água e, consequentemente, nas estimativas de recarga. 
Ao contrário do método WTF, os modelos numéricos de fluxo em regime transiente permitiram estimar os valores de recarga subtraindo-se os efeitos decorrentes da extração de água por poços de bombeamento. Assume-se que os valores de recarga obtidos pela calibração de modelos numéricos de fluxo em regime transiente são mais realistas por reproduzir a variabilidade espacial de litologias e o efeito do bombeamento. Contudo, é necessário ressaltar que os modelos de fluxo podem agregar elevado grau de incertezas, em decorrência da indisponibilidade de informações em quantidade e qualidades suficientes para a devida parametrização do modelo, particularmente em áreas com fortes heterogeneidades geológicas. Acrescenta-se ainda que as soluções dos modelos numéricos não possuem singularidade e modelos com parametrizações distintas podem fornecer resultados igualmente calibrados.

\section{CONCLUSÕES}

As peculiaridades da área de estudo, marcada por heterogeneidades litológicas, presença de LNAPL no meio poroso e sob efeito do bombeamento dos sistemas de remediação, dificultam estimativas confiáveis de recarga. 0 valor médio de recarga calculado pelo método WTF na área de estudo corresponde a $25 \%$ da precipitação acumulada anual.

Os modelos em regime transiente foram capazes de reproduzir a frequência e a amplitude da flutuação do NA nos 7 anos abarcados pela simulação, indicando que os valores de recarga obtidos estão calibrados. Os resultados indicam que a recarga é amplamente variável, sendo mais elevada em porções topograficamente planas e próximas dos divisores de fluxo e menores nas encostas e próximas das áreas de descarga, variando entre 9\% e 15\% da precipitação anual acumulada.

A diferença entre as estimativas de recarga por WTF e as simulações numéricas é decorrente do emprego de valores distintos de $S_{y}$. No caso dos modelos numéricos, os valores calibrados de $S_{y}$ representam o parâmetro "porosidade preenchível”, que são mais apropriados para estimativas de recarga por levarem em consideração o efeito de histerese da água durante os recorrentes ciclos de drenagem e embebição dos poros na zona onde ocorre a flutuação do NA.

\section{REFERÊNCIAS}

ACHARYA, S.; JAWITZ, J.W.; MYLAVARAPU, R.S. Analytical expressions for drainable and fillable porosity of phreatic aquifers under vertical fluxes from evapotranspiration and recharge. Water Resources Research, v. 48, n. 11, 2012.

CHILDS, E. C. The nonsteady state of the water table in drained land. Journal of Geophysical Research, v. 65, n. 2, p. 780-782, 1960.

DEPARTAMENTO DE ÁGUAS E ENERGIA ELÉTRICA. Disponível em: <http://www.daee.sp.gov.br/>. Acesso em: 02 mar. 2017.

FERNANDES, A. J. Tectônica cenozóica na porção media da Bacia do rio Piracicaba e sua aplicação à hidrogeologia. Tese (Doutorado em Recursos Minerais e Hidrogeologia). Instituto de Geociências, Universidade de São Paulo. São Paulo, 244 p, 1997.
HARBAUGH, A.W.; MODFLOW-2005, the U.S. Geological Survey modular ground-water model - the Ground-Water Flow Process. U.S. Geological Survey Techniques and Methods 6-A16. 2005.

HEALY, R.W.; COOK, P.G. Using groundwater levels to estimate recharge. Hydrogeology journal, v. 10, n. 1, p. 91-109, 2002.

JYRKAMA, M.I.; SYKES, J.F.; NORMANI, S.D. Recharge estimation for transient ground water modeling. Groundwater, v. 40, n. 6, p. 638-648, 2002.

KAYANE, I. Some problems relating to groundwater balance. Hydrological Sciences Journal, v. 28, n. 1, p. 125-137, 1983.

KING, A. C.; RAIBER, M.; COX, M. E.; CENDÓN, D. I. Comparison of groundwater recharge estimation techniques in an alluvial aquifer system with an intermittent/ephemeral stream (Queensland, Australia). Hydrogeology Journal, p. 1-19, 2017.

PEDE, M.A.Z. Flutuação do lençol freático e sua implicação na recuperação de hidrocarbonetos : um estudo de caso. Tese (Doutorado em Geociências e Meio Ambiente). 126 p. 2009.

RABELO, J.L.; WENDLAND, E. Assessment of groundwater recharge and water fluxes of the Guarani Aquifer System, Brazil. Hydrogeology Journal, v. 17, n. 7, p. 1733, 2009.

SCANLON, B.R.; HEALY, R.W.; COOK, P.G. Choosing appropriate techniques for quantifying groundwater recharge. Hydrogeology journal, v. 10, n. 1, p. 18-39, 2002.

SOPHOCLEOUS, M.A. Combining the soilwater balance and water-level fluctuation methods to estimate natural groundwater recharge: practical aspects. Journal of hydrology, v. 124, n. 3-4, p. 229-241, 1991.

SREEKANTH, J.; MOORE, C.; WOLF, L. Estimation of optimal groundwater substitution volumes using a distributed parameter groundwater model and prediction uncertainty analysis. Water Resources Management, v. 29, n. 10, p. 3663-3679. 2015.

TERAMOTO, E.H.; CHANG, H.K. Field data and numerical simulation of BTEX concentration trends under water table fluctuations: Example of a jet fuelcontaminated site in Brazil. Journal of contaminant hydrology, v. 198, p. 3747, 2017.

VAN GENUCHTEN, M. Th. A closed-form equation for predicting the hydraulic conductivity of unsaturated soils 1 . Soil science society of America journal, v. 44 , n. 5 , p. $892-898,1980$.

WANG, H.; GAO, J. E.; ZHANG, M. J.; LI, X. H.; ZHANG, S. L.; JIA, L. Z. Effects of rainfall intensity on groundwater recharge based on simulated rainfall experiments and a groundwater flow model. Catena, v. 127, p. 80-91, 2015.

YIN, L.; HU, G.; HUANG, J.; WEN, D.; DONG, J.; WANG, X.; LI, H. Groundwaterrecharge estimation in the Ordos Plateau, China: comparison of methods. Hydrogeology Journal, v. 19, n. 8, p. 1563-1575, 2011. 